\title{
A Strategic Communication Model for Sustainable Initiatives in Higher Education Institutions
}

\author{
By Lucille Mazo* \\ Iain Macpherson ${ }^{\dagger}$
}

\begin{abstract}
Communicating sustainable initiatives in higher education institutions presents a challenge, given that few to no universities possess or maintain a strategic communication plan that addresses the need to share this information effectively to stakeholders (students, faculty, staff, administrators, and community advocates). Drawing on secondary and primary research across universities in three countries, each representing distinct regional and national orientations - Canada, Ecuador, and Ukraine - the authors explain a sustainability/environmental communication model designed to be flexible enough for universal application, while providing strategic guidelines tailored to higher education institutions in each of its four described steps. The strategic communication model is informed by the critical synthesis of secondary research into two main areas of literature: (1) strategic communication theory and best practice; and (2) the organizational dissemination of sustainability initiatives, particularly within post-secondary institutions. Such secondary literature informs, and is in turn contributed to by, the authors' primary research that was conducted, which consists of three parts: (1) discourse analysis of relevant institutional documents and promotional materials; (2) interviews about current practices in sustainability-related communication, conducted with higher education sustainability administrators; and, (3) focus groups with students, examining participant awareness and assessment of their institution's sustainability communications. Based on such study, the authors advance a strategic communication model for sustainable initiatives, which comprises a four-step process based on a series of eight questions, with the first step providing comprehensive explication of a seven-component strategic planning framework that scales downward from the most abstract considerations to concrete tactics. In summary, the primary-and secondary-research data suggests that most universities, even if they implement sustainability initiatives or officially incorporate environmentalism into their institutional identity statements (mission, vision, etc.), fail to communicate these actions informatively and persuasively, thereby establishing widespread need for this paper's offered strategic guidance.
\end{abstract}

Keywords: strategic communication model, sustainability, higher education

\section{Introduction}

Through synthesized research findings and teaching insights, the authors collaboratively devised a comprehensive communication planning model that is based on a series of strategic questions designed to focus a higher education institution's communication approaches, and that includes a project-management framework guiding strategy and tactics along a continuum ranging from the most abstract and general considerations to the most concrete and specific actions. This model was conceived and developed in light of two main areas of analysis: (1)

\footnotetext{
* Assistant Professor and Chair, Department of Communication, Faculty of Fine Arts and Communications, MacEwan University, Canada.

${ }^{\dagger}$ Assistant Professor, Department of Communication, Faculty of Fine Arts and Communications MacEwan University, Canada.
} 
primary research involving institutional stakeholders of sustainable practices, and (2) historical and current literature on institutional sustainability campaigns and communication, especially within the post-secondary educational sector. This research study advises on how higher education sustainability advocates and administrators, and communications professionals, can apply the described model within their own institutions, in a resource-efficient manner, to meet a variety of information-provision and persuasive goals.

Few higher education institutions possess and maintain a comprehensive strategic communication plan designed to communicate critical information about their sustainable practice (Beveridge, MacKenzie, Vaughter, \& Wright, 2015; Vaughter, Wright, McKenzie, \& Lidstone, 2013). Consequently, students, faculty members, staff, and administrators, as well as external communities may not be aware of the work undertaken and accomplishments universities strive to achieve when affecting change through sustainability. As such, the following research questions were posed as a guideline for this research study: (1) What are the strategic communication approaches used by higher education institutions when informing others about their sustainable practices? (2) Do higher education institutions apply a specific model and framework to ensure that their practices in sustainability are communicated? As indicated within this study, there is a significant lack of knowledge regarding higher education institutions' efforts and activities involving sustainability. As such, a model is presented to assist and guide higher education institutions in strategically communicating their sustainable practices to stakeholders on campus and within local communities. Universities in Canada, Ecuador, and Ukraine were used as examples to demonstrate key points and to compare how they inform and persuade stakeholders regarding their sustainable practices.

\section{Literature Review}

A focus on sustainability by higher education institutions can be traced back to the 1978 United Nations International Environmental Education Programme (Vaughter et al. 2013). Scholarship on this matter has existed from that time, with a surge seen since the United Nations' 2002 Ubuntu Declaration called on educational institutes to infuse sustainability throughout all operations and curricula (Wright \& Horst, 2013). However, there remains a dearth of such research addressing organizational communications - higher-education institutions' information provision or promotions regarding sustainability initiatives. The studies that exist find near-universal failure to implement audienceattuned and audience-responsive strategic communication that succeeds in informing or persuading relevant institutional stakeholders (e.g., Wright \& Horst, 2013; Carpenter, Takahashi, Lertpractchya, \& Cunningham, 2016; Godfrey \& Feng, 2017).

This lacuna in the literature persists despite frequent acknowledgment of "the necessity of strong communication and leadership to initiate, maintain and drive sustainable ... policy" (Vaughter et al, 2013, p. 2260), as well as particularly pressing need for stakeholder engagement, given the higher education realities of 
faculty governance and student politics. Vaughter et al. (2013) also observe that most research on higher education sustainability consists of single case studies, as opposed to national or international comparisons, and they urge more such largescale, cross-contextual scholarship. This study assists in filling that gap, with our focus on stakeholder perceptions of higher education sustainability communications in Canada, Ecuador, and Ukraine.

In the overall literature, there is an emergent focus on personal perceptions of higher education sustainability among key stakeholders such as high-ranking administrators (e.g., Wright, 2010), faculty (e.g., Wright \& Horst, 2013), and students (Godfrey \& Feng, 2017). Some of this work addresses communication generally or implicitly. However, few studies assess the effectiveness of higher education sustainability communications. In one example of such research, Carpenter et al. (2016) report that "the extant evidence points toward a limited use of strategic communication in favour of intuition or past experiences" (p. 521). Godfrey and Feng (2017) note that environmental communications in general rely overmuch on appeals to scientific expertise, as opposed to recognizing "the necessity of incorporating human values and ... two-way dialogue" (p. 3). They also observe that "research on sustainable behaviour change has typically focused on quantitative results of survey-based or experimental research without extracting the deep insights available through qualitative approaches" (pp. 4-5). In their case study of one university's failure to inspire behavioural change among students, Godfrey and Feng urge theorists and practitioners to "explore new methods of reflexive, participatory communication to develop more meaningful and relevant campaigns aimed at changing [stakeholder] choices" (p. 19). This study's proposed strategic-communication model, focused on higher education sustainability campaigns, is a first step in that direction.

\section{Methodology}

In order to develop the strategic communication model, this study applied a mostly qualitative approach over a period of three years, which included a combination of three methods: (1) one-on-one interviews, (2) unobtrusive observation, and (3) focus group discussions. In addition, discourse and content analyses were conducted over a period of six years, which provided a critical basis for the development of the strategic planning framework.

\section{Sample}

Participants consisted of four groups located at three universities: students, faculty, administrators, and staff. Three university locations were visited for data collection purposes: Universidad San Francisco de Quito (USFQ), Quito, Ecuador (2014); MacEwan University, Edmonton, Canada (2015); and National University of Kyiv-Mohyla Academy (NaUKMA), Ukraine (2015). Data in the form of notes, transcripts, and recordings were combined from these three universities to determine commonalities, similarities, and dissimilarities about actual communicative strategies being employed within the context of sustainability. 
These data shaped and established the basic strategic communication model, as presented in the Discussion section (Figure 1).

Additionally, this study's profiled strategic-communication planning framework draws from an instructional rubric developed as the core component of an intermediate-level course on strategic communication planning. The planning framework, described in this paper, is designed for applicability to a wide range of communications categories. It has undergone successive reformulations over its six years of development, in response to feedback from both students and alumni applying it in their communications and advertising jobs.

Upon combining all of these methods of data collection through triangulation, the culminating findings informed the development of a strategic communication model that universities can utilize when identifying, organizing, and communicating critical information regarding their sustainable initiatives both internally and to external communities.

\section{Measures}

Measurement of communication strategies in relation to sustainable initiatives was based on a series of eight questions related to the identification, awareness, and actual use of these strategies at higher education institutions. As such, a dedicated participant questionnaire was developed to capture data relevant to this study's research questions. This instrument originated from first-hand discussions and emailed input from various stakeholders within MacEwan University, including students, faculty, and staff who were engaged in sustainable initiatives on campus. Their direct feedback on this instrument informed the composition of the questions, which were subsequently used when gathering data at the three universities included in this study. This participant questionnaire and the participant responses assisted in establishing this paper's profiled strategic communication model for sustainable initiatives in higher education.

\section{Results}

Qualitative primary- and secondary source research data produce a base finding that many universities do not possess and maintain a comprehensive strategic communication plan designed to communicate critical information about their sustainable initiatives (e.g., Beveridge et al., 2015; Vaughter et al., 2013). Consequently, students, faculty members, staff, and administrators, as well as external communities may not be aware of the accomplishments universities strive to achieve when affecting change in the key area of sustainability.

Data collection from MacEwan University, Canada; USFQ, Ecuador; and NaUKMA, Ukraine involved interviews, ethnographic unobtrusive observations, and focus group discussions. These data were used as a primary source and a guideline when developing the strategic communication model for sustainable initiatives in higher education institutions.

One-on-one in-depth interviews were conducted at two of the universities, MacEwan and USFQ, for the purpose of gathering data related to a series of defined questions focused on obtaining specific information about the sustainable 
practices that were currently being employed on campus (Table 1). All MacEwan participants $(100 \% ; n=5 / 5)$ were aware that a sustainability plan was being developed; however, only $40 \%(\mathrm{n}=2 / 5)$ knew that the plan included a communication component (university administrators). In the case of USFQ and NaUKMA universities, none of the students, faculty members, and staff were aware of any sustainability plan existing within their university governance and policies. More specifically, $85 \%(n=6 / 7)$ of those who were interviewed at USFQ identified the use of posters as the primary mode of communication that the university used to share information about sustainable initiatives on campus. As well, a focus group of primary stakeholders (students) at NaUKMA provided insights about their sustainable initiatives (Table 1). Overall, students, faculty, staff, and administrators indicated the need for more resources for communicating sustainability on campuses.

Table 1. Summarized Participant Data $(\mathrm{n}=20)$

\begin{tabular}{|c|c|c|c|}
\hline Questions & $\begin{array}{l}\text { Participant } \\
\text { (USFQ, Ecuador) } \\
\text { Individual interviews } \\
(\mathbf{n}=7)\end{array}$ & $\begin{array}{l}\text { Participant } \\
\text { (MacEwan, Canada) } \\
\text { Individual interviews } \\
(\mathbf{n}=5)\end{array}$ & $\begin{array}{l}\text { Participant } \\
\text { (NaUKMA, Ukraine) } \\
\text { Focus group } \\
(\mathbf{n = 8})\end{array}$ \\
\hline $\begin{array}{l}\text { Does your } \\
\text { university have a } \\
\text { sustainability plan } \\
\text { or direction? }\end{array}$ & $\begin{array}{l}\text { - No participants knew about a } \\
\text { dedicated sustainability plan } \\
\text { or direction. }\end{array}$ & $\begin{array}{l}\text { - All participants }(\mathrm{n}=5 / 5) \\
\text { were aware that an } \\
\text { institutional } \\
\text { sustainability plan was } \\
\text { being developed }\end{array}$ & $\begin{array}{l}\text { No participants knew } \\
\text { whether there was a } \\
\text { plan for sustainability. }\end{array}$ \\
\hline $\begin{array}{l}\text { If so, does it have a } \\
\text { component that } \\
\text { includes strategic } \\
\text { communications? }\end{array}$ & $\begin{array}{l}\text { No participants were aware } \\
\text { that there was a strategic } \\
\text { communications plan for } \\
\text { sustainability. }\end{array}$ & $\begin{array}{l}\text { - Two out of five }(40 \%) \\
\text { participants knew } \\
\text { about a } \\
\text { communication } \\
\text { component within the } \\
\text { sustainability plan. }\end{array}$ & $\begin{array}{l}\text { No participants knew } \\
\text { whether there was a } \\
\text { sustainability plan or } \\
\text { whether it contained a } \\
\text { communication } \\
\text { component. }\end{array}$ \\
\hline $\begin{array}{l}\text { If not, in what } \\
\text { direction do you } \\
\text { think your } \\
\text { university should } \\
\text { focus on regarding } \\
\text { sustainability? }\end{array}$ & $\begin{array}{l}\text { Five out of seven }(71.4 \%) \\
\text { participants indicated that } \\
\text { posters were a basic method } \\
\text { of communicating } \\
\text { sustainability on campus. }\end{array}$ & $\begin{array}{l}\text { Four out of five (80\%) } \\
\text { participants agreed that } \\
\text { the current direction } \\
\text { for sustainability was } \\
\text { important, such as the } \\
\text { reduction of waste } \\
\text { through recycling }\end{array}$ & $\begin{array}{l}\text { All participants }(n=8 / 8) \\
\text { indicated that there } \\
\text { should be more } \\
\text { attention towards } \\
\text { sustainable initiatives. } \\
\text { Developing a plan for } \\
\text { sustainability is good. }\end{array}$ \\
\hline $\begin{array}{l}\text { What strategies } \\
\text { have you seen used } \\
\text { to communicate } \\
\text { and apply } \\
\text { sustainable } \\
\text { practices on your } \\
\text { campus }(e s) ?\end{array}$ & $\begin{array}{l}\text { - Two out of seven }(28.5 \%) \\
\text { participants identified that } \\
\text { the university communicated } \\
\text { information about } \\
\text { sustainable practiced during } \\
\text { a fire ban. } \\
\text { - Five out of seven ( } 71.4 \%) \\
\text { identified posters as the key } \\
\text { communication tool for } \\
\text { sustainability on campus. }\end{array}$ & $\begin{array}{l}\text { Four out of five }(80 \%) \\
\text { participants identified } \\
\text { social media, website, } \\
\text { events, emails, and } \\
\text { posters as } \\
\text { communication } \\
\text { strategies being used } \\
\text { on campus. }\end{array}$ & $\begin{array}{l}\text { All participants }(n=8 / 8) \\
\text { identified the existence } \\
\text { of a recycling program } \\
\text { on campus. }\end{array}$ \\
\hline $\begin{array}{l}\text { Which } \\
\text { communication } \\
\text { strategies do you } \\
\text { think are effective } \\
\text { when information } \\
\text { about sustainable } \\
\text { practices on your } \\
\text { campus(es) are } \\
\text { being shared? }\end{array}$ & $\begin{array}{l}\text { - Three out of seven }(42.8 \%) \\
\text { participants indicated that } \\
\text { the promotion of } \\
\text { sustainability should target } \\
\text { specific disciplines for } \\
\text { greater effect. } \\
\text { - All participants }(n=7 / 7) \\
\text { indicated that posters were } \\
\text { very effective. }\end{array}$ & $\begin{array}{l}\text { - All participants }(\mathrm{n}=5 / 5) \\
\text { identified that social } \\
\text { media strategies } \\
\text { seemed to connect } \\
\text { with the greatest } \\
\text { number of students, } \\
\text { faculty, staff, and } \\
\text { administrators, as well } \\
\text { as external } \\
\text { organizations. }\end{array}$ & $\begin{array}{l}\text { Seven out of eight } \\
\text { (87.5\%) of participants } \\
\text { indicated that social } \\
\text { media and posters } \\
\text { would work well on } \\
\text { their campus. }\end{array}$ \\
\hline
\end{tabular}




\begin{tabular}{|c|c|c|c|}
\hline $\begin{array}{l}\text { What impact do } \\
\text { you think } \\
\text { communication } \\
\text { strategies have on } \\
\text { sustainable } \\
\text { practices in } \\
\text { universities? }\end{array}$ & $\begin{array}{l}\text { One out of seven }(14.2 \%) \\
\text { participants said that the } \\
\text { results are good. Campaigns } \\
\text { go through the basics such } \\
\text { as recycling. }\end{array}$ & $\begin{array}{l}\text { - Three out of five }(60 \%) \\
\text { of participants said that } \\
\text { there is a significant } \\
\text { impact on the } \\
\text { attendance of } \\
\text { sustainable events that } \\
\text { are hosted by the } \\
\text { university. }\end{array}$ & $\begin{array}{l}\text { - Five out of eight } \\
\text { (62.5\%) participants } \\
\text { indicated that sharing } \\
\text { information about the } \\
\text { recycle program has } \\
\text { been somewhat } \\
\text { effective. More needs } \\
\text { to be done. }\end{array}$ \\
\hline $\begin{array}{l}\text { Would a common } \\
\text { model that outlines } \\
\text { communication } \\
\text { strategies } \\
\text { regarding } \\
\text { sustainable } \\
\text { practices be } \\
\text { useful? }\end{array}$ & $\begin{array}{l}\text { Two out of seven }(28.5 \%) \text { of } \\
\text { participants said that they } \\
\text { think people around the } \\
\text { world believe in the same } \\
\text { things. This would support a } \\
\text { model. }\end{array}$ & $\begin{array}{l}\text { - All participants }(\mathrm{n}=5 / 5) \\
\text { indicated that a } \\
\text { common model for } \\
\text { strategic } \\
\text { communication for } \\
\text { sustainability would be } \\
\text { great. }\end{array}$ & $\begin{array}{l}\text { - All participants }(\mathrm{n}=8 / 8) \\
\text { said that a model } \\
\text { would be very helpful } \\
\text { for our Eco group and } \\
\text { university. }\end{array}$ \\
\hline $\begin{array}{l}\text { What common } \\
\text { criteria do you } \\
\text { think should be } \\
\text { included as part of } \\
\text { a strategic } \\
\text { communications } \\
\text { model for } \\
\text { sustainability? }\end{array}$ & $\begin{array}{l}\text { The majority of participants } \\
(85.7 \% ; n=6 / 7) \text { believed that } \\
\text { interracial communication } \\
\text { between universities and } \\
\text { among countries would help } \\
\text { to spread everywhere. }\end{array}$ & $\begin{array}{l}\text { - Four out of five }(80 \%) \\
\text { participants indicated } \\
\text { that the criteria should } \\
\text { include social media } \\
\text { usage, in-person } \\
\text { engagement, and } \\
\text { events on campus. }\end{array}$ & $\begin{array}{l}\text { The majority of } \\
\text { participants }(87.5 \% ; \\
\mathrm{n}=7 / 8) \text { suggested that } \\
\text { social media, posters, } \\
\text { and events would be } \\
\text { good. }\end{array}$ \\
\hline $\begin{array}{l}\text { Is there anything } \\
\text { more that you } \\
\text { would like to } \\
\text { mention? }\end{array}$ & $\begin{array}{l}\text { This type of research should } \\
\text { be done more deeply and go } \\
\text { down to the root of the } \\
\text { problem, so we can see the } \\
\text { real effects. }\end{array}$ & $\begin{array}{l}\text { I am excited about this } \\
\text { model. It will be very } \\
\text { useful. }\end{array}$ & $\begin{array}{l}\text { - There needs to be more } \\
\text { strategies to } \\
\text { communicate } \\
\text { sustainability. }\end{array}$ \\
\hline
\end{tabular}

\section{Discussion}

\section{The Model}

The strategic communication model for sustainable initiatives in higher education includes four steps consisting of a series of critical questions that are posed to guide a university towards the development of a strategic communication approach within its larger institutional plan. Given that communication strategies are often overlooked by institutions when developing a strategic plan for sustainable initiatives, the need for a model that institutions can apply as a guideline becomes critical when seeking successful outcomes for their sustainable initiatives.

For example, in the case of MacEwan University, there has been a significant movement towards establishing an institutional sustainability plan; however, communication strategies to inform stakeholders of these initiatives are a minimal part of this plan. In the case of USFQ, there is no institutional plan for sustainability, and subsequently there is no strategic communication plan to share sustainable achievements that are being accomplished by this university. This is an interesting case, given that Ecuador is one of the first countries that included "environmental rights" in its constitution and policies. Reviewing the transcripts of NaUKMA makes clear the critical need for an institutional plan that addresses their sustainable initiatives, overall, inclusive of communication strategies both internally to students, faculty, and administrators, as well as to external 
stakeholders such as NGOs. A comprehensive institutional strategic plan for sustainability would provide key direction and focus for this Ukrainian university. As such, in each case, all three universities could benefit from the review, guidance, and application of this strategic communication model for sustainable initiatives in higher education (Figure 1).

Figure 1. Strategic Communication Model for Sustainable Initiatives in Higher Education Institutions

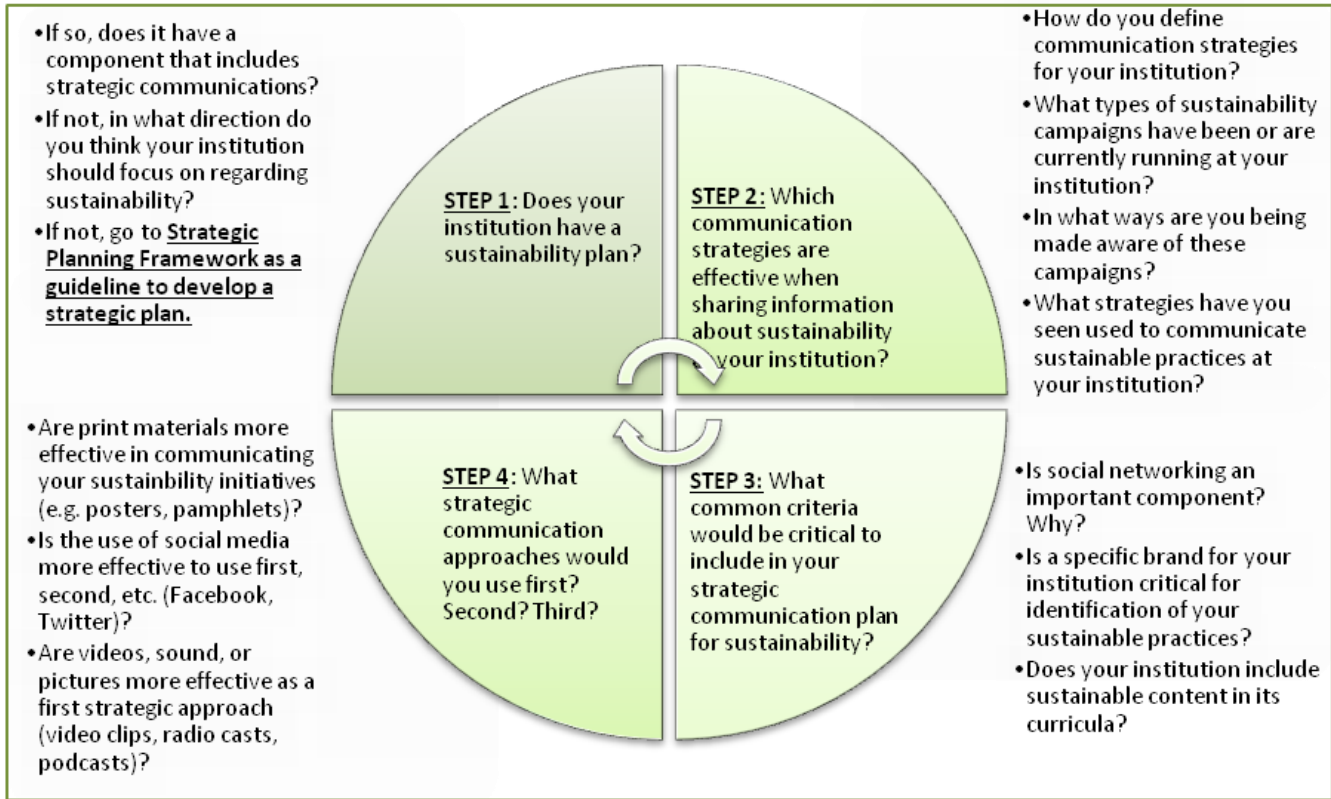

Step 1: Does your institution have a sustainability plan? Based on the discussions within the three universities, it was clearly evident that the first step to this model must focus on determining whether an institutional sustainability plan existed. While a strategic communication plan for sustainability can be developed independently, it follows that greater success at sharing sustainable initiatives within a university can be achieved when an institutional strategic plan inclusive of sustainability and strategic communication policies, practices, and processes significantly supports communication procedures. In the case of MacEwan University, an institutional strategic plan exists, as well as a sustainability strategic vision and mission that form part of this larger plan. Ongoing work is being accomplished, as the institution reviews its sustainability practices and approaches, including the area of communication. Most notably, MacEwan University has included a review process of its sustainability plan, which allows for changes to the plan, as required. Stakeholders of this plan include students, faculty, staff, and administrators who work collaboratively to achieve the goal of sustainability and to communicate it through events, initiatives, and curricula. Universities that have not developed an institutional strategic plan that includes sustainable initiatives should consider doing so in order to align with their overall vision. The following provides a framework that higher education institutions can apply as a guideline when developing a strategic communications plan for sustainability. 
The Framework. As part of Step 1: Does your institution have a sustainability plan?, in the strategic communication model for sustainable initiatives in higher education, a framework for strategic planning was developed as a guideline for higher education institutions to apply when developing a basic plan focused on sustainability and communication strategies. The strategic planning framework for higher education sustainability communications is aimed at a balance of conceptual comprehensiveness and simplicity. Its structure and process, and its constituent components, are detailed so as to guide implementation. Moreover, this information is infused with insights from primary and secondary research. However, the authors have also sought to maintain explanatory parsimony. Partly, this decision involves alignment towards the ultimate "imagined audience" of endusers: the institution's administrators and staffers tasked with the planning scheme's application and operation. The framework's aimed-for simplicity corresponds also with the goal of maximal flexibility. This framework can be tailored to the wide range of institutional contexts and situational contingencies that may be faced by sustainability stakeholders, at any given higher education organization. Considerable work was also completed, in analyzing primary qualitative data across distinct regional and national milieus - Canada, Ecuador, and Ukraine - to ensure that this strategic communication model has robust crosscultural/societal applicability.

It should be noted that communication plans based on the following strategic components can take a processual structure that is similar in terms of sequential steps - i.e., a preliminary focus on "big picture" issues such as alignment with broader organizational identity and strategy, followed by ever-narrower foci, such as the communication-situation analysis and then the audience analysis, and only thereafter a concentration on such "tactical" concerns as key-message crafting, media-channel selection, budget, and timelines. However, it is also frequently the case that all such plan elements overlap, being considered roughly simultaneously, and very recursively, with planning at one level of abstraction or concreteness altering or determining deliberations and actual rollout at the other levels.

The strategic communication planning framework is organized into the following sections, with a focus on sustainable initiatives in higher education institutions:

i. Alignment of plan with organizational identity

ii. Alignment of plan with organizational strategy

iii. Communication-situation analysis

iv. Audience analysis

v. Planning specifics

vi. Key messaging

vii. Operational matters

i. Alignment of plan with organizational identity: Founding figure of public relations theory J.E. Grunig has repeatedly emphasized (e.g., Grunig, 1992; Grunig, Grunig, \& Dozier, 2002) that, if proposed communication plans are to be officially and meaningfully implemented by higher education institutions, then planners must win the active support 
of the "dominant coalition" (Cyert \& March, 1963) - management and other influencers who make the requisite decisions - as well as staffers who will be tasked with carrying out the plan and its policies. This is especially the case when, as with sustainability campaigns, the plans promote changes in thought and behaviour (Kanihan, Hansen, Blair, Shore, \& Myers, 2013). And as in any communication situation, a key tactic here lies in framing for common ground (Conger, 2008). This often involves presenting one's case with reference to the message recipients' (students, faculty, and administrators) pre-existing knowledge, attitudes, interests, and concerns (Ross, 2013; Walker, 2015).

In the case of higher education institution stakeholders, it is often wise for communication planners, just as for any other change agent, to establish that their initiatives advance, or at least align with, the higher education institution's officially declared mission, vision, and values. It has become common practice for institutions to craft separate mission and vision statements, the former being more concrete and action-based, the latter being more long-term, abstract, and affective. Vision statements are often elaborated upon with lengthier documentations of organizational essence and aspirations, variously conceived and conveyed as "values," "philosophy," "pillars," "culture," etc. In recent years, it has become increasingly common for organizations of all types to affirm their broader societal obligations, often by way of CSR ("corporate social responsibility") declarations and metrics. Such avowals frequently include environmental stewardship, which is frequently couched in sometimesbroader terms of "sustainability" (Scandelius \& Cohen, 2016; Vaughter, McKenzie, Lidstone, \& Wright, 2016).

This trend is prominent in the higher education sector (Vaughter et al., 2016), although here as elsewhere, research has found that institutions are often keener on signing "sustainability" declarations than on crafting accordant policies, much less thoroughly implementing them (Beveridge et al., 2015). That being noted, when a commitment to environmental responsibility expressly exists in one or more official identity statements, this offers leverage to communication professionals and other advocates championing a particular sustainability campaign. It is well-established that organizational actors can often advance many types of agenda, for or against change, by invoking organizational identity statements - mission, vision, values or the like - in support of their stance (Crimando \& Riggar, 2006; Scandelius \& Cohen, 2016). This requires rhetorical skills (and even debating prowess), especially for sustainability exponents in higher education institutions that do not explicitly state environmentalism as an aspect of their identity. In such cases, it is advisable for such actors to scrutinize official identity statements, and relatable organizational communications such as CSR documents, for acknowledgements of broad societal obligations, and to explicitly link communication plans with those utterances.

Examining the three universities within this study demonstrated that only one out of three has aligned with its university's vision, mission and 
institutional strategic plan (MacEwan University), while the others have not completed this critical and important step within the strategic communication model for sustainable initiatives.

ii. Alignment of plan with organizational strategy: Not all organizational actors extend great "buy in" to official identity statements, either because of personal temperament or because those statements are poorly drafted and inadequately disseminated. For such stakeholders, communicationplan alignment with these abstract principles will have little influence (and perhaps limited intelligibility). However, another "big picture" exists, to which organizational orientation is more universal, and with which successful communication plans will also align so as to establish "common ground": the organization's overarching strategic environment and direction, or particular broad strategies which the communication plan is meant to assist. If records detailing such strategies do not exist or are not accessible, communication planners should nevertheless conduct research to ascertain the sponsoring organization's big-picture strategic situation. This would include the reading of relatable primary documents and secondary sources, as well as interviews with well-informed organizational representatives.

It is typically prudent to emphasize or explain to "dominant coalitions" (plan-approving and plan-implementing agents) how the proposed environmental campaign will advance the organization's broadest interests, aside from those the plan concerns most closely improving a higher education institutions' environmental record. Such connections with strategy at large will vary in nature and extent. For examples, strengthening an institution's sustainability might help in distinguishing it from competitors, or dovetail with its revitalization of a municipal area. In relation to this study, all three universities were at different stages of determining the existence of an institutional strategic plan, identifying whether this plan included sustainability, and then deciding how to insert the strategic communication part of this plan into these processes.

iii. Communication-situation analysis: However tightly or tangentially aligned a communication plan is presented as being with its sponsoring organization's broad strategic orientations, a narrower set of planencompassing strategic considerations must be engaged in depth. Higher education communication planners need to perform, and present results from, an intensive investigation of the strategic concerns and contexts impinging most directly upon the proposed sustainability campaign factors recommending the plan and those posing challenges to be overcome in its implementation. These include internal factors, such as available communication resources, and external factors such as competitor communications, relevant laws, and broad societal trends and shifts. In the case of all communication plans, the relevance of such situational circumstances principally involves types and aspects of 
communication. Therefore, the researchers have termed this plan component the communication-situation analysis, or alternatively communication-environment scan. In this, the communication prefix is being added to two decades-old terms and concepts - situation(al) analysis and environment(al) scanning - synonymously deployed throughout the fields of strategic planning, project management, and social science (e.g., Aguilar, 1967; van Velsen, 1967).

The type of situational-analytical research conducted will primarily depend on the methodological background of planners and the resources available. However, planners should also determine and consider what research evidence will prove most credible - intelligible and persuasive to the "dominant coalition" of organizational stakeholders who will approve and implement the plan (Grunig, 1992; Grunig et al., 2002). In the case of communication plans for many or most organizations, managerial audiences to be convinced prefer quantitative evidence, or require it for releasing resources, because the numerical data and positivist attestations of predictability make quantified findings seem more accountable (Ströh, 2007; Walker, 2015). However, such is not always the case, perhaps especially in a higher education institute with academic governance, where important internal stakeholders will be faculty with varied methodological expertise and preferences. Communication planners should make efforts to discover the research orientations of significant organizational agents, and take this into consideration when devising and describing their situation and audience analyses.

For situational-, audience- or other analysis, all communication plan research, including higher education institutional research in the area of sustainability, can consist of any combination of quantitative, qualitative, primary, and secondary study. Broad approaches and specific methods include communication audits and critical-incident case studies; mass mail- or email surveys; in-depth interviews and focus groups; datacomputation, from organizational-network analysis to social-media metrics; and the review or text analysis of primary documents alongside relevant secondary literatures - journalistic, scholarly and grey (i.e., white papers, government reports) (Hargie \& Tourish, 2009).

Almost universally, any such situational research is conducted, and/or explained in plan presentations and reports, via factor-based models that chart the key contexts and concerns isolated for consideration. Such situation-analytical rubrics have proliferated for many decades, across all fields of strategic planning, project management, and social science. Perhaps the oldest of these, and still the one most frequently drawn upon, is S.W.O.T: Strengths, Weaknesses, Opportunities and Threats. This fourfactor framework appeared in the 1960s though its exact origins remain disputed (Helms \& Nixon, 2010; Everett, 2014). It is meant to guide situational analysis by pinpointing the most plan-salient internal traits of a plan-sponsoring organization - its strengths and weaknesses - and external circumstances over which the organization exercises less control - the opportunities and threats. 
As with all prominent conceptual models, over the years debates have arisen over the effectiveness of S.W.O.T. regarding its intended purpose. Naysayers raise a range of objections. It is frequently charged that the would-be tool categorizes considerations but without ranking them or otherwise offering any actual advice (e.g., Hill \& Westbrook, 1997), thereby producing "banal or misleading results" (Everett, 2014, p. 62). Along even starker epistemological lines, some argue that the very attempt to isolate and bullet-list contextual considerations understates their interrelatedness and ambiguity, by stating or suggesting a degree of predictability that is unrealistic - and hence, ironically, un-strategic (e.g., Ströh, 2007). Such detractors usually urge that the plan-relevant organizational environment should be analyzed highly holistically, especially through intensive scholarly secondary research, and explained in presentations and reports through an expository manner, with minimal reliance on bullet lists and charts. The researchers of this current study have found a more expository/narrative mode of explanation to be viable, and even preferable, in certain communication-plan cases; this depends on plan specifics, planner methodological training, and audience expectations of dissemination.

Probably more widespread than wholesale S.W.O.T. rejection are moves to modify the matrix, frequently by rearranging or slightly altering its four categories, so as to emphasize them differently, conceptually and/or rhetorically. Perhaps the most prevalent such rejigging is T.O.W.S, advanced on grounds that it is advisable to first foreground, when planning and/or explaining a plan, the external factors of threats and then opportunities. In opposite vein, S.W.O.C or S.W.O.CH replaces the diresounding threats with constraints or challenges. Such minor modifications may make conceptual and/or rhetorical sense depending on the communication situation for both the plan itself and its presentation/ reporting - i.e., the "dominant coalition" organizational audience assessing and a plan and hopefully approving and/or implementing it.

As well, outright factor-based alternatives to S.W.O.T. abound, based on more or just different factors. As its acronym indicates, T.E.L.E.S.C.O.P.I.C. O.B.S.E.R.V.A.T.I.O.N.S. offers twenty-two of them (Panagiotou, 2013). Most contenders aim like S.W.O.T. for parsimony in the number of featured factors. Probably the second-most common situation-analytical model is P.E.S.T., which analyzes an organization and/or strategy in terms of broad external contexts: political, economic, socio-cultural, and technological. As with S.W.O.T., strategic-planning fields teem with P.E.S.T. acronym inversions, alterations, and additions. The most relevant of these for sustainability plans would be P.E.S.T.L.E, which isolates legal and environmental concerns for specific assessment, as opposed to nestling such matters within the traditional four categories.

P.E.S.T. and its variants concentrate consideration upon "macro-scale" external contexts. These tend to be wrongly overlooked in S.W.O.T. frameworks, since that model does not impel contemplation of broad, deeply underlying strategic factors - ones with perhaps indirect causality. 
There is therefore a tendency for its implementers to focus too narrowly, even somewhat myopically, on immediate and relatively obvious internalities (strengths, weaknesses) and externalities (opportunities, threats) (Everett, 2014). But conversely, it could be charged that P.E.S.T., with its "big picture" (macro) orientation, allows for excessive abstraction. The two models' respective focuses - "micro" (S.W.O.T.) versus "macro" (P.E.S.T.) - can operate complementarily; therefore, it is quite common to combine frameworks, by categorizing the P.E.S.T. (L.E.) factors as an organization's (or strategy's) external opportunities and threats. Of course, reliance upon such a composite model means care must be taken that analysis and/or explanation thereof does not err on the side of complexity, awash in a superabundance of bullet points and chart lines.

The researchers find a good measure of validity in the aforementioned critiques of factor-/bullet-based situation-analytical matrix-models. Probably inevitably, these frameworks intrinsically under-emphasize the in-fact irreducible interrelationships, uncertainties, and nuances attendant upon any strategic plan - communication-centric, sustainability-related, or otherwise. However, so long as this limitation of their idealtype abstraction (Weber, 1904/1949) is at all times borne in mind, any of the factor-based frameworks on offer may serve well as an insight-sparking brainstorming heuristic during planning sessions. The authors have often found a P.E.S.T.L.E./S.WO.T. amalgamation to work well in such regards.

Whether or not planners find factor-based models practicable for indepth analysis, they often serve well as explanatory frameworks - utilized when the environment scan, however it has been conducted, is outlined as a section of planning presentations and written reports. This decision can depend on one's audience for such project deliverables. The authors, in their communication-plan consulting and teaching, have found that an expository/narrative mode of explanation, with few to no bullet-based factor frameworks, sometimes proves the most advisable option for more scholastically inclined audiences - who may well be sitting in judgment on higher education sustainability-campaign communication plans. However, for their non-academic counterparts, lay-professional terminology and graphics, such as S.W.O.T, often function as a shorthand, lingua franca, common frame of reference between planners and audiences.

iv. Audience analysis: As just described, communication-situation analysis scales downward a plan's abstraction from deliberation upon organizational identity and broad strategic direction, by grounding the plan in a narrower, more empirical range of contextual considerations. Even more so, the audience analysis of key targeted stakeholders intensifies a plan's focus upon concrete, operational specifics. The plan-relevant traits of these audiences constitute a communication-situational context crucial enough that it typically warrants its own plan section. And while environment-scan rubrics such as S.W.O.T. and P.E.S.T. are sometimes applied to communication-plan audiences, these plan sections are more 
commonly treated with distinctive methodological approaches and explanatory frameworks.

Most methodological questions and debates covered in the previous section apply also to audience analysis. Plan-targeted people are studied with the full variety of available methods - primary, secondary, quantitative and qualitative - from surveys and in-depth interviews to data analytics and historical or philosophic readings. While mixed-method approaches exist, in the case of audience analysis, the usual epistemic divide between quantitative and qualitative paradigms is especially stark. Theorists and practitioners of either camp tend to stake strong claims on incommensurably opposite basic assumptions about knowledge, and hence strategy (Ross, 2013).

Quantitative audience research tends to be predicated on a fundamental orientation toward targeted stakeholders as an amalgam of calculable demographics and "psychographics," the latter traits (sociocultural and psychological orientations) being admeasured with the sophisticated data analytics that are increasingly available, such as the tracking of online behaviour. Within the quantitative paradigm, audiences are perceived and presented as basically predictable, and implicitly controllable, for plan purposes (Coombs \& Holladay, 2012). Quantitative primary-research methods for capturing audience characteristics usually involve computerized mass data - population-representative surveys, network-analytical software, social-media analytics and the like. Secondary scholarship drawn upon for theoretic guidance tends to be rooted in science and positivist social science, from statistics and market reports to cognitive psychology and neuroscience.

As with situation-analytical reports, plan-sponsoring organizational stakeholders generally have a preference for audience explanation based on numeric "hard" data. This can stem from personal inclination or their need for the accountability attributed to such numbers when plan approval is moved upward. However, as mentioned, in the case of higher education institutions with faculty governance and student politics, "dominant coalitions" can have different expectations, and methodological orientations, in this regard (Carpenter et al., 2016). Sustainabilitycampaign communication planners are therefore advised to perform some rough audience analysis on their presentation/report audiences, in addition to that directed at the end recipients of their plan's messages.

Whereas quantitative research emphasises the extent to which subjects are measurable, predictable, and subject to influence, qualitative analysts take more cue from the movie-industry audience adage "nobody knows anything." The design and delivery of their communications is often based on belief that "audience complexity precludes ever truly knowing how an audience will respond" (Ross, 2013, p. 96). Accordingly, Bocchi (1991) labels such approaches "intuition-driven" in contradistinction to more quantitative "cognitive-based" audience-analytical methodologies (as cited in Ross, 2013). This "intuition" plays out variably in communicationplanning terms, but it typically involves an emphasis on operational 
flexibility: shorter time-frames, contingency options, and ongoing audience testing (Ross, 2013). In terms of specific research methods, the most commonplace qualitative primary-research practices are in-depth interviews, focus groups, observations, ethnography, and rhetorical/ discourse analysis. Secondary-research sources are eclectic, spanning journalism and audience-relevant fields of mostly qualitative scholarship: history, anthropology, intercultural communication, and social theory.

Quantitative or qualitative, audience analysis is usually conducted and/or conveyed through factor-based frameworks, as is the case with situation analysis, although it can likewise instead be explained through the expository mode (sans bullet lists). While S.W.O.T. and other situationanalytical rubrics are sometimes applied to audiences, usually communication planners utilize purpose-built audience-analytic models. There are many such schemata on offer, and the authors have found Ross's (2103) "deep audience analysis" (DAA) model highly applicable to a range of environmental communications, because it is designed for those specific purposes.

In DAA, after or alongside primary and secondary audience research, environmental-communication stakeholder segments are attitudinally categorized into three factors: (1) "the sources of information they privilege" (Ross, 2013, p. 95) ("mainstream news," scientific reports, celebrity testimonials, social media, etc.); (2) "their motivations towards environment-related action" (p. 95), meaning their general attitudes regarding environmentalism; and, (3) "the commonplace elements likely to be most useful in constructing environment-related communication" (p. 95). Commonplaces, a term drawn from classical rhetoric, refers to words, phrases, or visuals that elicit strong positive or negative reactions in audiences, and around which their attitudinal orientations coalesce. Once this three-factor stakeholder profile is completed, it is used "to shape, or reshape ... messaging to emphasize elements indicated as positive $(+)$ and avoid elements indicated as negative (-)" (p. 99).

v. Planning specifics: Attention must be paid to any communication plan's purpose and the specific actions that will be undertaken to this end, all of which must be overviewed in the introduction of presentations and reports. Such deliberations will guide the formulation of all other plan components (Walker, 2015). Yet they will typically do so in a highly recursive manner, and the authors have found that a plan's "whys and hows" usually come clearest after the previously discussed research-intensive tasks are engaged: alignment with organizational identity and overarching strategic orientation; communication-situation analysis; and audience analysis. The authors also generally find it makes sense in communication-plan presentations and reports to offer the most concentrated coverage of planning specifics after explaining the research that informed the design of such tasks.

Wherever planning specifics are addressed in a communication campaign's presentation and reporting, it is common in strategic planning 
of all types to conceive such activities, and convey that information, in a scaling down of abstraction from general to specific. And as with many plan components, a ready-made rubric is often drawn upon - in this case G.O.S.T.: Goals, Objectives, Strategies, and Tactics. As articulated through this framework, a plan may have one or a few overarching goals, which express what a plan seeks to achieve in relatively general terms - for example, a higher education sustainability communication campaign, or one of its major planks, that aims to inspire faculty to engage in more environmentally-focused research (a parallel goal might target teaching). Such goals manifest in one or more objectives, which state measurable aims - for example, increase faculty environment-related research publications by five percent in two years' time.

One or more strategy will be attached to each objective. Strategies describe in relatively general terms the course of action to be undertaken in pursuit of that objective - for example, launch an internal award for environmental scholarship. Tactics are the steps taken to realize each strategy, and in communication plans, these often centre around media/ channel choice. Much here is made of social media, especially on grounds that its interactivity and informality both enables and necessitates a strategically and ethically superior "symmetrical" mode of communication, one giving equal voice to stakeholders and organizational communicators (e.g., Grunig, 1992; Grunig et al., 2002). However in environmental campaigns, as with other communication plans, equal attention should be paid to other media.

This includes older media, which may for key stakeholders remain the primary, preferred, or most credible information channel (Ledford, 2012). In higher education institutions as with other large organizations, such platforms include websites, internal email lists, newsletters, and printed materials such as posters. Planners must also factor in face-to-face groupand interpersonal communications; this reportedly holds especially true in "decentralized" institutions such as higher education institutions (Carpenter et al., 2016). An environmental-research award could be publicized alongside "media events" such as visiting-scholar lectures by prominent environmental researchers, who can also host workshops explaining how to infuse a sustainability focus into various disciplines and academic interests. The award can also be promoted through meetings with individual "dominant coalition" representatives, and in presentations at departmental/committee gatherings.

vi. Key messages: Just as audience analysis is a communication-situation context warranting its own plan section, likewise the devising and description of key messages is so crucial a tactical consideration that it constitutes a stand-alone plan component. Indeed, while the selection and crafting of key messages will be influenced by all other substantive plan elements - from organizational identity to budgeting constraints and affordances - those factors fundamentally function to support the delivery of key messages to their targeted stakeholders. Nevertheless, insufficient 
attention to key messages - the primary vehicles of persuasion and information - is a commonplace communication-plan failure, in conception, deployment and presentations/reports. This failure frequently results in communication campaigns seeming or being unclearly distinguished from other or broader types of strategic plans.

Key messaging remains under-theorized (McGrath, 2007; Pomering, Johnson \& Noble, 2013). However, the researchers of this study have developed an explanatory and strategic framework for message crafting, based on two levels of conception - general/abstract and specific/concrete. First, based on situational and audience analysis, as well as considerations such as available media channels, planners need to settle on messaging in the broadest sense, often labelled themes or schemas: the basic ideas and/or feelings plans aim to impart and instil, through the content of specific messages as well as their tone and/or aesthetic.

Based on overall themes/schema, specific messages are crafted. These are typically linguistically based: key words, key phrases, and brief blurbs, to be embedded, repetitively, in various communications. But they may include, or even only be, numbers (which should be rounded up or down, to secure audience remembrance, whenever this does not compromise clarity or honesty). As well, they may involve other sensory inputs, to various degrees. Font style and size imply a theme, as does a verbal message's conveyance via different paralinguistic qualities (accent, tone, etc.) or musical jingle. Key messages can also be primarily visual: organizational colour schemes, logos, mascots, uniforms or dress codes, and architectural or interior-décor details. Finally, depending on the plan, such as a branding campaign or product launch, it may even make sense to base key messages, at least partly, on sense channels such as touch or smell. In all such cases, key messages should be concise and memorable, and linkable to plan goals/ objectives, and perhaps also, to the plansponsoring organization's official identity statements.

Communication plans typically have one or two primary audience groups, perhaps along with one to a few ancillary audiences. It is wise to conceptualize themes and craft key messages that are broad or strategically ambiguous enough to inform or appeal to more than one such stakeholder segment (Scandelius \& Cohen, 2016). However, depending on plan scope, planners may be creating a number of themes and messages for different target audiences. All or several of these may be featured in a written report, depending on its pagination limits. For most presentations, planners should focus on featuring just a few key messages, perhaps offering them as examples - probably no more than two messages and two themes per profiled audience segment, and in no case more than four key messages discussed, explained in some detail, and displayed as text or through visual mockups. For example, a higher education sustainability campaign aimed at boosting environmental research might be based on the theme that all disciplines contribute to sustainability, and it could involve the following three slogans, aimed respectively at faculty in fine arts, communication or 
English, and accounting or economics: "Art Sustains"; "What Does Green Mean?"; "Sustainability Counts".

vii. Operational matters: As with all planning projects, communication plans and their presentations/reports must attend to those most concrete and chart-friendly of details: workflow and budgets. However, like all other plan elements, these should be settled upon strategically/ tactically, with consideration to such matters as best or worst times for campaign events, and whether tasks can be parceled out to volunteers or undertaken in costsharing partnership with other organizations. Finally most communication plans will involve, and their presentations/reports conclude by covering, post-rollout or ongoing assessments of goal/objective attainment. Such appraisements will be based on primary research; however, as with all other research-intensive plan components, planners may rely on any mix of quantitative or qualitative methods, from follow-up interviews to ROI metrics. In making this decision, planners should bear in mind the plansponsoring "dominant coalition" who will be evaluating the plan, including its proposed self-evaluations.

Step 2: Which communication strategies do you think are effective when sharing information about sustainability at your university? Identifying the most effective communication strategies within a higher education institution requires collaborative and consistent consultation with all stakeholders. Academic governance at universities provides a unique structure that enables students, faculty, staff, administrators, and sometimes external stakeholders to discuss, consult, and decide on critical matters regarding core institutional vision, mission, and goal-oriented directions. It is this academic structure that is used by stakeholders of sustainable initiatives for the purpose of advancing and communicating information both internally and externally.

Diversity of dissemination practices is key to ensuring that this step is successful -creativity is fundamental when employing communication strategies in the delivery and sharing of information about sustainability. Print, online, social media, television, radio, in-person announcements, and community events are examples of some of these strategies. Selecting one or a combination of several communication strategies that are designed to fill any gaps of information access for stakeholders who are in receipt of sustainable initiatives is a common approach amongst universities. Given the diversity and level of engagement that the three universities (MacEwan, USFQ, and NaUKMA) possessed regarding communication strategies for sustainability, each institution used unique approaches to its dissemination processes. As shown in Table 1, these universities used various communication strategies to distribute messages about their sustainable initiatives, such as posters, email, and events that promoted sustainability on their campuses. In the case of USFQ and NaUKMA, a significant part of their sustainability initiatives involved collaboration with external organizations. For example, NaUKMA consistently partnered with Nongovernment Organizations (NGOs) within and outside of Ukraine, which included a worldwide United Nations initiative on education and responsibility, under the 
auspices of UNESCO, a worldwide United Nations initiative on education and sustainability. In the case of USFQ, the institution worked with environmental groups located in different parts of Ecuador. These groups were primarily situated near the Ecuadorian Rainforest, where the oil and gas industry has extracted these products from the earth for decades. With MacEwan University, minimal engagement with NGOs has been established, leaving a gap in its ability to communicate its sustainable practices on a global level. International communication strategies are key to establishing a global presence for a university's work in sustainability. Social media campaigns, focused media storms, and creative branding centered on key sustainable initiatives are critical to a successful sharing of information.

Finally, it is important to note that while online information was effective for all three universities, study participants from each studied university emphasized that printed posters located on campus remained a core strategy for communicating sustainable initiatives to students, faculty, staff, and administrators.

Step 3: What common criteria would be critical to include in your strategic communication plan for sustainability? Consistently applying common criteria in a higher education institution's strategic communication plan for sustainable initiatives establishes a foundation of basic approaches that, when combined, provide a set of benchmarks that align with an institution's goals. As such, the following provides a comprehensive list of common criteria that were derived from research data gathered from stakeholders at three universities (MacEwan, USFQ, and NaUKMA).

Common criteria for a strategic communication plan for sustainability:

- Printed materials: print communication materials such as posters, brochures, cards, pictures, bookmarks, magazines, and journals are consistently being used to communicate sustainable initiatives. At a time when online is the most-discussed mode of communication strategies, with its interactivity and quick pace of sharing information, the impact that printed materials have on sending clear and constant messages to students, faculty, staff, and administrators is still significant.

- Social media: access to all stakeholders within a higher education institution is usually established through various social media accounts (Facebook, Twitter, Linkedin, Snapchat, etc.). Universities should share information about sustainable initiatives through more than one of these media. Success in using these media involves identifying the ones that students, faculty, staff, and administrators use the most and ensuring that these channels are regularly employed when sharing information.

- Website: a dedicated website that contains and shares critical information about sustainable initiatives at a higher education institution acts as a base for various levels of information. A website also acts as a way to authenticate the initiative or event that is being organized and demonstrates an established link with the university. Accountability and identity is established using this mode of communication. 
- In-person: when stakeholders of sustainability come together at an event, the in-person communication impact can be significant. Developing and establishing an annual event that assembles like-minded advocates, students, faculty, staff, and administrators who support these initiatives sends a strong and persuasive message because human-to-human interpersonal communication strategies are highly effective when sharing information. Often, a special cause creates a common bond that online communication may not effectively construct.

Step 4: What strategic communication approaches would you use first? Second? Third? The order in which communication strategies can be applied is relative in nature and organic in structure. Each higher education institution experiences a unique set of stakeholders and conditions set within its academic and local communities. Strategically organizing communication strategies to share sustainable initiatives make a media campaign successful. However, based on the three universities that were examined for this study, the data suggested the following potential order of communication approaches:

1. Social media communication strategies (Facebook, Twitter, etc.);

2. Websites that support social media communications;

3. Posters at different locations on campus and within the community;

4. In-person events that occur regularly at specified and known times;

5. Groups that meet for collaborative discussions and forums.

\section{Conclusion}

This study offered a comparative, longitudinal understanding of how three universities employed strategic communication approaches when sharing information about their sustainable initiatives. Each university used a unique approach, based on the level of engagement of their institution regarding strategic institutional planning. The data suggested that when a university has established an institution-wide strategic plan, it is a direct influence on establishing a strategic communication plan, overall. Consequently, this sets the platform in which communication strategies for sustainable initiatives are included. However, many universities do not have a communication strategy, and if so, they do not necessarily include sustainability in their plans.

Through primary qualitative research, and secondary literature review, a strategic communication model for sustainable initiatives in higher education institutions was developed to provide a set of guidelines for universities to use when developing their own communication plans. Considerable and significant initiatives are being developed and established through universities, a platform and forum from which sustainability is discussed, contemplated, and acted upon. Universities are positioned in society to affect positive social change in the area of sustainable initiatives. This strategic communication model can be applied to increase the effectiveness of disseminating these initiatives to the academic, local, and international communities. 


\section{References}

Aguilar, F. J. (1967). Scanning the Business Environment. New York, NY.: Macmillan Co. Beveridge, D., MacKenzie, M., Vaughter, P., and Wright T. (2015). Sustainability in Canadian post-secondary institutions: The interrelationships among sustainability initiatives and geographic and institutional characteristics. International Journal of Sustainability in Higher Education, 16(5), 611-638.

Carpenter, S., Takahashi, B., Lertpratchya, A.P., \& Cunningham, C. (2016). Greening the campus: A theoretical extension of the dialogic communication approach. International Journal of Sustainability in Higher Education, 17(4), 520-539.

Conger, J. A. (2008). The Necessary Art of Persuasion. Boston, MA.: Harvard Business Press.

Coombs, T. W., \& Holladay, S. J. (2012). Fringe public relations: How activism moves critical pr toward the Mainstream. Public Relations Review, 38(5), 880-887.

Crimando, W., \& Riggar, T. F. (2006). Internal marketing: Promoting your "brand" within the organization. Journal of Rehabilitation Administration, 30(2), 115-131.

Cyert, R. M., \& March, J. G. (1963). A Behavioral Theory of the Firm. Englewood Cliffs, NJ.: Prentice Hall.

Everett, R. F. (2014). A Crack in the foundation: Why SWOT might be less than effective in market sensing analysis. Journal of Marketing \& Management, 1(1), 58-78.

Godfrey, D. M., \& Feng, P. (2017). Communicating sustainability: Student perceptions of a behavior change campaign. International Journal of Sustainability in Higher Education, 18(1), 2-22.

Grunig, L. A. (1992). Power in the public relations department. In J. E. Grunig (Eds.), Excellence in Public Relations and Communication Management (483-501). Hillsdale, NJ.: Lawrence Erlbaum Associates.

Grunig, L. A., Grunig, J. E., \& Dozier, D. M. (2002). Excellent Public Relations and Effective Organizations: A Study of Communication Management in Three Countries. Mahwah, NJ.: Lawrence Erlbaum Associates.

Hargie, O., \& Tourish, D. (2009). Auditing Organization Communication. New York, NY.: Routledge.

Helms, M. H., \& Nixon, J. (2010). Exploring SWOT analysis - where are we now? A review of academic research from the last decade. Journal of Strategy \& Management, 3(3), 215-251.

Hill, T., \& Westbrook, R. (1997). SWOT analysis: It's time for a product recall. Long Range Planning, 30(1), 46-52.

Kanihan, S. F., Hansen, K. A., Blair, S., Shore, M., \& Myers, J. (2013). Communication managers in the dominant coalition: Power attributes and communication practices. Journal of Communication Management, 17(2), 140-156.

Ledford, C. J. W. (2012). Changing channels: A theory-based guide to selecting traditional, new, and social media in strategic social marketing. Social Marketing Quarterly, 18(3), 175-186.

McGrath, C. (2007). Framing lobbying messages: Defining and communicating political issues persuasively. Journal of Public Affairs, 7(3), 269-280.

Panagiotou, G. (2003). Bringing S.W.O.T. into focus. Business Strategy Review, 14(2), 8-10.

Pomering, A., Johnson, L.W., \& Noble, G. (2013). Advertising corporate social responsibility: Results from an experimental manipulation of key message variables. Corporate Communications: An International Journal, 18(2), 249-263. 
Ross, D. G. (2013). Deep audience analysis: A proposed method for analyzing audiences for environment-related communication. Technical Communication, 60(2), 94-117.

Scandelius, C., \& Cohen, G. (2016). Achieving collaboration with diverse stakeholders: The role of strategic ambiguity in CSR communication. Journal of Business Research, 69(9), 3487-3499.

Ströh, U. (2007). An alternative postmodern approach to corporate communication strategy. In E. L. Toth (Eds.), The Future of Excellence in Public Relations and Communication Management (199-220). London, UK: Routledge.

van Velsen, J. (1967). The extended case method and situational analysis. In A. L. Epstein (Eds.), The Craft of Social Anthropology (129-149). London, UK: Tavistock.

Vaughter, P., Wright, T., McKenzie, M., \& Lidstone, L. (2013). Greening the ivory tower: A review of educational research on sustainability in post-secondary education. Sustainability, 5(5), 2252-2271.

Vaughter, P., McKenzie, M., Lidstone, L., \& Wright, T. (2016). Campus sustainability governance in Canada. International Journal of Sustainability in Higher Education, $17(1), 16-39$.

Walker, R. (2015). Strategic Management Communication for Leaders (3rd ed.). Stamford, CT.: Cengage Learning

Weber, M. (1904/1949). Objectivity in social science and social policy. In E. Shils \& H. Finch (Eds. and Trans.), The Methodology of the Social Sciences (49-112). Glencoe, IL: Free Press of Glencoe.

Wright, T. (2010). University presidents' conceptualizations of sustainability in higher education. International Journal of Sustainability in Higher Education, 11(1), 61-73.

Wright, T., \& Horst, N. (2013). Exploring the ambiguity: What faculty leaders really think of sustainability in higher education. International Journal of Sustainability in Higher Education, 14(2), 209-227. 